\title{
ATIVIDADES FÍSICA, EDUCATIVA E DE DANÇA: UM ESTUDO DOS VALORES PESSOAIS DOS CONSUMIDORES IDOSOS
}

\author{
Luciana Torres Souza Kelly \\ Mestrado em Administração pela Universidade Estácio de Sá - UNESA \\ Professor da Universidade Barra Mansa - UBM \\ E-mail: own.luizkelly@uol.com.br (Brasil)
}

\section{RESUMO}

Este artigo apresenta como objetivo principal identificar os valores pessoais dos consumidores idosos dos serviços de atividades física, educativa e de dança, sob o aspecto motivacional hedônico e utilitário. Adotou-se o modelo de cadeia meios-fim de Gutman (1982), o qual sugere que a pesquisa deve utilizar uma abordagem qualitativa através da entrevista em profundidade no levantamento dos dados e da análise de conteúdo. Uma fase da metodologia é quantitativa, decorrente da tabulação das consequiências e valores em tabelas, visando construir os mapas hierárquicos, os quais se constituem em diagramas de frequiência. Por meio dos resultados indicados nos mapas hierárquicos de valor foi possível observar que os valores e benefícios associados à participação em cada atividade são tanto de interesse individual quanto coletivo, e tanto de natureza hedônica quanto utilitária. Constatou-se através dos resultados, a identificação de valores convergentes e divergentes apontando o perfil heterogêneo do consumidor idoso indicando que a cultura, as vivências, as experiências e as realidades atuais corroboram para a manifestação de um valor pessoal característico na sua vida. E nas situações de compra e utilização de serviços, apresentam como meta a aquisição de novas amizades e a experimentação de momentos variados (com novidades) na vida diária.

Palavras-chave: Comportamento do consumidor idoso; Valores pessoais; Atividade física; atividade educativa e atividade de dança.

REMark - Revista Brasileira de Marketing, São Paulo, v. 10, n. 3, p. 24-45, set./dez. 2011. 


\section{INTRODUÇÃO}

O processo de envelhecimento da população vem ocorrendo intensamente nos últimos anos, em consequiência da queda dos índices de natalidade, associada à queda da mortalidade, além do fato de as pessoas estarem vivendo mais, transformando o perfil da população (ONU, 2007).

O Brasil, em poucas décadas (por volta do ano 2020), tende a ser o país mais envelhecido da América Latina e, ainda, o $6^{a}$ país mais idoso do mundo, com aproximadamente 32 milhões de pessoas com idade superior a 60 anos (ONU, 2007).

Quanto aos aspectos ligados à saúde, a participação em atividades físicas leves e moderadas pode retardar os declínios funcionais dos idosos, sendo importante que os governos promovam o envelhecimento ativo e saudável, com o intuito de manter o bem-estar e a qualidade de vida na terceira idade. A previsão é de que atingiremos a proporção de $15 \%$ de idosos em relação à população total no prazo de 25 anos (OMS, 2008).

Diante deste contexto, surge o interesse pela realização de um estudo específico que identifique a natureza dos motivos (utilitário ou hedônico) e os valores pessoais que têm o consumidor idoso na participação das atividades física, educativa e de dança.

Segundo Moschis (2003), estudos demonstram que o comportamento deste segmento é mais sensível às suas necessidades e estilos de vida, que por sua vez são influenciados pelas mudanças que ocorrem ao longo da vida (como casamento, nascimento dos filhos, aposentadoria, perda do (a) parceiro (a), etc.) e pelas experiências vividas. Ocorrem mudanças no decorrer desta fase da vida, e estas precisam ser compreendidas para que melhor se atenda às necessidades deste segmento.

Ainda Mendonça \& Teixeira (2002) concluem que, entender as necessidades próprias dos idosos, descobrindo e aprendendo a atender às suas expectativas, também sob o ponto de vista do consumo e do marketing, seria uma forma de reconhecer sua identidade como consumidor. Atendendo este mercado em expansão sem desprezar suas necessidades e limitações.

As atividades no âmbito físico, educativo e de dança, necessitam estar em destaque nos estudos, por representarem um importante papel no uso consciente e qualitativo do tempo disponível do idoso, característico das mudanças advindas da organização social do trabalho.

Destacamos alguns fatores que compõem a limitação deste estudo: a interpretação de dados qualitativos, por sua natureza não objetiva, é difícil e sujeita a erros; a escassez de estudos sobre a identificação dos valores encontrados em pessoas idosas que participam de atividades física, educativa e de dança; em se tratando de entrevistados idosos, aproveitando ao máximo as ligações,

REMark - Revista Brasileira de Marketing, São Paulo, v. 10, n. 3, p. 24-45, set./dez. 2011. 
optou-se por conduzir as entrevistas de forma que se realizassem ligações diretas na sequiência A-C$\mathrm{V}$ e através deste procedimento a pesquisadora eliminou o surgimento de ligações indiretas; a restrição que o estudo apresenta em incluir somente idosos aposentados entre 60 e 85 anos, vinculados à Associação dos Aposentados e Pensionistas de Volta Redonda e moradores na cidade de Volta Redonda e Barra Mansa, o que ocasiona a impossibilidade de generalizar os resultados dos estudos para idosos do mesmo segmento de idade, em outros contextos ou locais geográficos; devido à característica exploratória da obtenção dos atributos, etapa inicial para o desenvolvimento dos mapas laddering, não há garantias de que estes reproduzem a lista de atributos essenciais para descrever o fenômeno; e a seleção dos sujeitos por conveniência reduz a possibilidade de generalização do estudo, onde o mesmo não poderá ser generalizável a todos os idosos aposentados nesta faixa etária que realizam atividades física, educativa e de dança; os resultados podem sofrer outras interpretações.

Os valores pessoais são considerados como metas motivacionais que expressam alvos que a pessoa quer atingir na sua vida (TAMAYO \& PASCHOAL, 2003). Os valores, portanto, têm um papel dominante no comportamento do consumidor idoso e nas suas atitudes e reações em relação à participação em atividades física, educativa e de dança.

$\mathrm{O}$ estudo contribui para um entendimento acerca dos motivos que conduzem o consumidor idoso a participar dos serviços de atividades física, educativa e de dança. Favorecendo também a canalização eficaz dos investimentos nestas atividades, de forma a atender expectativas e necessidades evidentes. Além de possibilitar o estudo comportamental e atitudinal que a pesquisa fornece.

\section{FUNDAMENTAÇÃO TEÓRICA}

\subsection{COMPORTAMENTO DO CONSUMIDOR IDOSO}

Para Moschis (1994) o comportamento do consumidor maduro é resultado de um processo de envelhecimento e de experiências através da vida que difere de indivíduo para indivíduo; em conseqüência de diversos aspectos dinâmicos, como a história e o contexto cultural no quais os seres humanos estão inseridos. As pessoas envelhecem como seres biológicos, psicológicos e sociais, e até como seres espirituais, e isso ocorre de maneira diferente através do espaço de vida, e

REMark - Revista Brasileira de Marketing, São Paulo, v. 10, n. 3, p. 24-45, set./dez. 2011. 
não se pode assumir que as pessoas com idades semelhantes tenham as mesmas experiências ou o mesmo processo de envelhecimento.

Com o passar dos anos as pessoas assumem novos papéis, elas tendem a redefinir suas necessidades de consumo e prioridades. Moschis $(1994,1996)$ cita que muitos especialistas em marketing têm centrado seus esforços em oferecer produtos e serviços que preencham o "novo" tempo disponível dos aposentados. Os consumidores idosos passam pela transição de papéis, produtos e serviços posicionam e facilitam a adaptação dos consumidores aos novos papéis.

As pessoas idosas tornam-se consumidores potenciais de experiências que os coloquem em pleno contato com a vida e com o afeto. Tendem a procurar lugares onde possam ampliar suas redes de contatos, como clubes para terceira idade, que promovem: bailes, viagens, jogos e chás da tarde. As experiências adquiridas passam a ser fonte de prazer e alegria (SCHEWE, 1991).

\subsection{ENVELHECIMENTO}

Em 1982, a Organização Mundial de Saúde (OMS) determinou que a etapa inicial do envelhecimento ocorresse a partir dos 60 anos de idade. É este estágio que se define como terceira idade, cuja expressão é usada para definir pessoas com idade igual ou superior a 60 anos. Este fato é justificado por este público estar aposentado nesta faixa etária, caracterizando um novo tempo em suas vidas ( FARIA, 2004).

Gobbi (2001), em seus estudos sobre envelhecimento, ressalva que alterações morfológicas e funcionais decorrentes do avanço da idade, em grande parte, especialmente as funcionais, estão mais ligadas à falta de exercícios físicos. $\mathrm{O}$ autor destaca que a taxa de algumas alterações biopsicossociais pode ser alteradas de modo positivo, se o indivíduo idoso incorporar esse estilo de vida ativo, mostrando que o organismo mais velho não perde sua capacidade de treinamento, pode melhorar, manter ou diminuir sua taxa de declínio de aptidão funcional.

O envelhecimento é parte do processo de vida, em que, com o passar do tempo, as capacidades vão dando espaço às limitações. Dependendo da filosofia de vida e dos valores pessoais e sociais, para alguns o envelhecimento pode ser um período vazio, sem valor, inútil, sem sentido; já para outros pode ser um tempo de liberdade, de desligamento de compromissos profissionais, de fazer atividades que não se teve tempo de realizar, de aproveitar a vida.

Moschis (1994) afirma que o processo de envelhecimento das pessoas ocorre de forma diferente através do espaço da vida e que não se pode assumir que pessoas com idades semelhantes

REMark - Revista Brasileira de Marketing, São Paulo, v. 10, n. 3, p. 24-45, set./dez. 2011. 
dividam as mesmas experiências, ou tenham o mesmo processo de envelhecimento. $\mathrm{Na}$ apresentação dos quatro processos através dos quais os indivíduos envelhecem (biologicamente, psicologicamente, socialmente e espiritualmente).

Schewe \& Balazs (1992) apresentam que este segmento tem uma característica que se destaca em termos de comportamento de consumo, definiram como sendo esta "estilo de vida cíclico: as pessoas maduras, ao se verem sem o compromisso de cuidar dos filhos e, com 20 a 30 anos de vida pela frente, resolvem reviver as melhores partes de suas vidas”. Quer aproveitar a vida, buscar qualidade e conveniência, e tem poder de consumo. No entanto, é experiente e exigente e, difícil de conquistar.

\subsection{ATIVIDADES FÍSICA, EDUCATIVA E DE DANÇA}

Quando as pessoas atingem a terceira idade, elas começam a preocupar-se com o nível de utilização de seu tempo. Elas começam a procurar atividades que preencham seu espaço livre e que constituam novas experiências (FLEISCHER \& PIZAM, 2002).

A terceira idade pode ser caracterizada como a grande fase da possibilidade do lazer, de realização pessoal e de investimento em si próprio. O lazer suscita atitudes ativas no decorrer da utilização do tempo livre, como a participação consciente e voluntária na vida social, opondo-se ao isolamento e ao recolhimento social, e a exigência de um progresso pessoal livre, pela busca de um equilíbrio entre o repouso, a distração e o desenvolvimento contínuo e harmonioso da personalidade (PAPALÉO NETTO, 1996).

Neugarten (1968) afirma que os idosos se dão conta de que "há muito para se viver" e tornam-se ansiosos por participar do maior número de atividades possível nos seus últimos anos de vida. Destaca em seus estudos de gerontologia que, quando as pessoas alcançam o estágio maduro da vida, tornam-se preocupadas com sua auto-realização. Desta forma, procuram atividades de autopreenchimento e experiências. Muller (1996) esclarece que este desejo motiva os aposentados a "explorar" o mundo enquanto eles ainda dispõem de condições físicas para tanto.

O público da terceira idade busca contato com novas pessoas, novas culturas, participação em eventos de confraternização e a vivência de experiências diferenciadas, aliadas com o meio ambiente, ou ainda, ligadas à religiosidade (MOLETTA, 2000).

O lazer dos idosos está ligado apenas a atividades do seu dia-a-dia, à conversa com amigos e familiares e atividades físicas mais calmas, como a caminhada (DIAS \& SCHWARTZ, 2002). Em

REMark - Revista Brasileira de Marketing, São Paulo, v. 10, n. 3, p. 24-45, set./dez. 2011. 
suas pesquisas, sobre a representação do lazer na vida, justificando a busca por melhor qualidade de vida e a ocupação prazerosa do tempo disponível. Para elas a concepção do lazer está sempre associada à distração e à diversão e, em relação às atividades mais vivenciadas nos momentos de lazer, encontram-se a prática de atividade física e a confecção de trabalhos manuais, assim como, os passeios, as visitas e as conversas com os amigos (DIAS \& SCHWARTZ, 2004).

Destacamos a iniciativa da Associação dos Aposentados e Pensionistas de Volta Redonda (AAPVR) em realizar uma parceria com o Centro Universitário de Volta Redonda (UNIFOA), onde os idosos associados têm a oportunidade de aprender e aperfeiçoar conhecimentos na área de informática, promovendo a inserção destes no universo tecnológico, elevando a auto-estima e a auto-realização.

\subsection{ATRIBUTOS}

Os atributos são construtos físicos e psicológicos através dos quais os consumidores descrevem ou diferenciam produtos e serviços (VALETTE-FLORENCE \& REPACHI, 1991).

De acordo com Vriens \& Hofstede (2000), os atributos concretos podem ser definidos como as características físicas diretamente observáveis em um produto, a exemplo do peso, cor, material, etc. Para Bostchen, Theles \& Pieters (1999) os atributos abstratos são as características intangíveis pertencentes a determinado produto como a marca, estilo e desempenho.

Amaral \& Nique (2000) afirmam que cada produto é visto como um conjunto de atributos, com capacidades diferentes de trazer benefícios e satisfazer às necessidades buscadas na fase de avaliação de alternativas do processo de compra. As características dos produtos e serviços são comparadas com especificações e padrões existentes dos consumidores.

Zeithaml (1988) categoriza os atributos em extrínsecos e intrínsecos, onde os atributos extrínsecos referem-se a componentes físicos e suas respectivas características funcionais; os atributos intrínsecos não fazem parte desta composição física do produto ou serviço como, por exemplo, sua marca.

O papel dos atributos é compreendido quando eles são integrados em um modelo de meios e fim reunindo as concepções de atributos, benefícios, custos e valor que funcionam como os meios utilizados nas avaliações do consumidor amparando a decisão de compra (o fim). Dependendo da categoria do produto o consumidor valoriza os atributos intrínsecos ou extrínsecos ( ZEITHAML,1988).

REMark - Revista Brasileira de Marketing, São Paulo, v. 10, n. 3, p. 24-45, set./dez. 2011. 
Moschis (1992) ressalta que a satisfação do consumidor maduro é que este adquire experiência pelos vários anos de contato com o mercado, resultando em um grande conhecimento de produto, desenvolvendo desse modo estratégias de compra efetivas, que parecem evitar uma resposta de insatisfação. Percebe-se neste momento uma forte ênfase no aspecto cognitivo do comportamento deste consumidor. No caso do consumidor de serviços, pela intangibilidade predominante, talvez seja mais difícil o desenvolvimento deste tipo de estratégia.

\subsection{FATORES MOTIVACIONAIS}

A motivação trata de um processo complexo que representa o ponto de partida de todo o comportamento do consumidor (WELLS \& PRENSKY, 1996).

O entendimento dos motivos humanos é importante para as empresas porque ele permite que elas entendam e possam prever o comportamento humano no mercado (SCHIFFMAN \& KANUK, 2002, p.59).

As necessidades e desejos do consumidor são responsáveis pelo início do processo de motivação. As necessidades e desejos não satisfeitos podem ser classificados como sendo: utilitários ou hedônicos. Utilitária quando existe o desejo de obter algum fim funcional ou prático; e hedônica quando se trata de uma necessidade de experiência, envolvendo respostas ou fantasias emocionais ( SOLOMON, 2002).

\subsection{VALORES PESSOAIS}

Segundo Jolibert \& Baumgartner (1997), motivação é a capacidade de se obter satisfação a partir de um estímulo. Para esses autores as motivações são conscientemente traduzidas em termos de valores.

De acordo com Sheth, Mittal \& Newman (2001), "valores são estados / finalidades da vida, os objetivos pelos quais as pessoas vivem". Para Rokeach (1973) um valor "é uma crença duradoura em que um modo específico de conduta ou estado definitivo de existência é pessoal ou socialmente preferível a um modo inverso ou oposto de conduto ou estado definitivo de existência". Ainda acrescenta que valores são estruturas psicológicas resultantes de experiências pessoais, sociais e culturais.

REMark - Revista Brasileira de Marketing, São Paulo, v. 10, n. 3, p. 24-45, set./dez. 2011. 
Valores pessoais refletem as escolhas que o indivíduo faz de uma variedade de Valores sociais ou sistemas de valores ao qual o indivíduo é exposto. Apesar de serem influenciados pelos valores sociais dos grupos a que pertencem, os indivíduos selecionam e escolhem os valores sociais para desenvolver seus próprios valores.

Os valores implicam necessariamente uma preferência, uma distinção entre o importante e o secundário, entre o que tem valor e o que não tem. Assim, a essência dos valores parece ser permitir a sua hierarquização. A organização hierárquica de valores pressupõe que o indivíduo não se relacione com o mundo físico e social como um observador que assiste a um espetáculo, mas como um ator que participa e que se envolve (TAMAYO, 2007).

\subsection{ESCALA DOS TIPOS MOTIVACIONAIS DE TAMAYO}

Para Tamayo \& Paschoal (2003), cada conjunto motivacional possui suas metas específicas e a estrutura motivacional não se apresenta de forma estática. Ela é considerada dinâmica e seus componentes motivacionais se relacionam entre si por meio de diversas polaridades.

Tamayo (2007) afirma que "[...] a originalidade do conceito de hierarquia de valores é que ela permite a comparação de indivíduos, grupos sociais e culturas não somente em termos de cada um dos valores, mas particularmente, no plano das prioridades axiológicas". De acordo com suas pesquisas, em 1981 os valores que ocuparam os seis primeiros lugares foram: família, paz, liberdade, auto-respeito, felicidade e sabedoria, e foram os mesmos que haviam sido apontados no ano de 1968.

A escala dos tipos motivacionais identificados tanto no Brasil como em outras culturas estão listados no quadro 1.

Quadro 1- Tipos motivacionais propostos por Tamayo (2007).

\begin{tabular}{c|c}
\hline TIPOS & VALORES CORRESPONDENTES \\
MOTIVACIONAIS & Valores que estão relacionados ao serviço de interesses individuais \\
\hline Hedonismo & Bem sucedido, capaz, ambicioso, inteligente, esperto e influente \\
\hline Auto-realização & Poder, autoridade, reconhecimento social e riqueza \\
\hline Poder social & Criatividade, liberdade, auto-respeito, independência, curiosidade e \\
Autodeterminação & $\begin{array}{r}\text { capidade para escolher as suas próprias metas } \\
\hline\end{array}$
\end{tabular}

REMark - Revista Brasileira de Marketing, São Paulo, v. 10, n. 3, p. 24-45, set./dez. 2011. 


\begin{tabular}{c|c} 
Conformidade & Valores que visam interesses coletivos \\
\hline Benevolência & Amor, trabalho e amizade \\
\hline Segurança & $\begin{array}{c}\text { Ordem social, segurança familiar, segurança nacional, reciprocidade } \\
\text { de favores }\end{array}$ \\
\hline Tradição & Respeito pela tradição, moderado e ciente dos meus limites \\
\hline Estimulação & Vida variada, vida excitante e audacioso \\
\hline Filantropia & Justiça social, igualdade, paz, união com a natureza, protetor do \\
ambiente
\end{tabular}

Fonte: Adaptado de Tamayo (2007).

Conforme ilustra a Figura 1, os cinco tipos de valores que expressam interesses individuais (autodeterminação, estimulação, hedonismo, realização e poder social) ocupam uma área que é oposta àquela reservada aos três conjuntos de valores que expressam interesses coletivos (benevolência, tradição e conformidade). Os tipos motivacionais segurança e filantropia (constituídos por valores que expressam interesses tanto individuais como coletivos) situam-se nas fronteiras dessas duas áreas. Ocorre compatibilidade entre os tipos de valores adjacentes (estimulação e hedonismo, tradição e conformidade) e conflito entre os tipos de valores situados em direções opostas (estimulação e conformidade, hedonismo e tradição).

A estrutura entre os valores e entre os tipos motivacionais constituídos por eles pode ser sintetizada em duas dimensões bipolares verificadas empiricamente no Brasil (Tamayo \& Schwartz, 1993). Conforme a Figura 1, o eixo "abertura à mudança" versus "conservação" orienta os valores com base na motivação da pessoa a seguir os seus próprios interesses intelectuais e afetivos por caminhos incertos e ambíguos, em oposição à tendência a preservar o status quo e a segurança que ele gera no relacionamento com os outros. Em um dos pólos desse eixo situam-se os valores relativos à "estimulação" e "autodeterminação" e, no outro, os referentes à "segurança", “conformidade" e "tradição". O eixo "autopromoção" versus "auto-transcendência", apresenta, num dos extremos, os valores que integram a "filantropia" e a "benevolência". Esse eixo ordena os valores com base na motivação da pessoa para promover os seus próprios interesses, mesmo à custa dos outros, em oposição a transcender as suas preocupações egoístas e promover o bem-estar dos outros e da natureza (TAMAYO, 2007).

REMark - Revista Brasileira de Marketing, São Paulo, v. 10, n. 3, p. 24-45, set./dez. 2011. 
Figura 1- Estrutura Bidimensional dos Valores

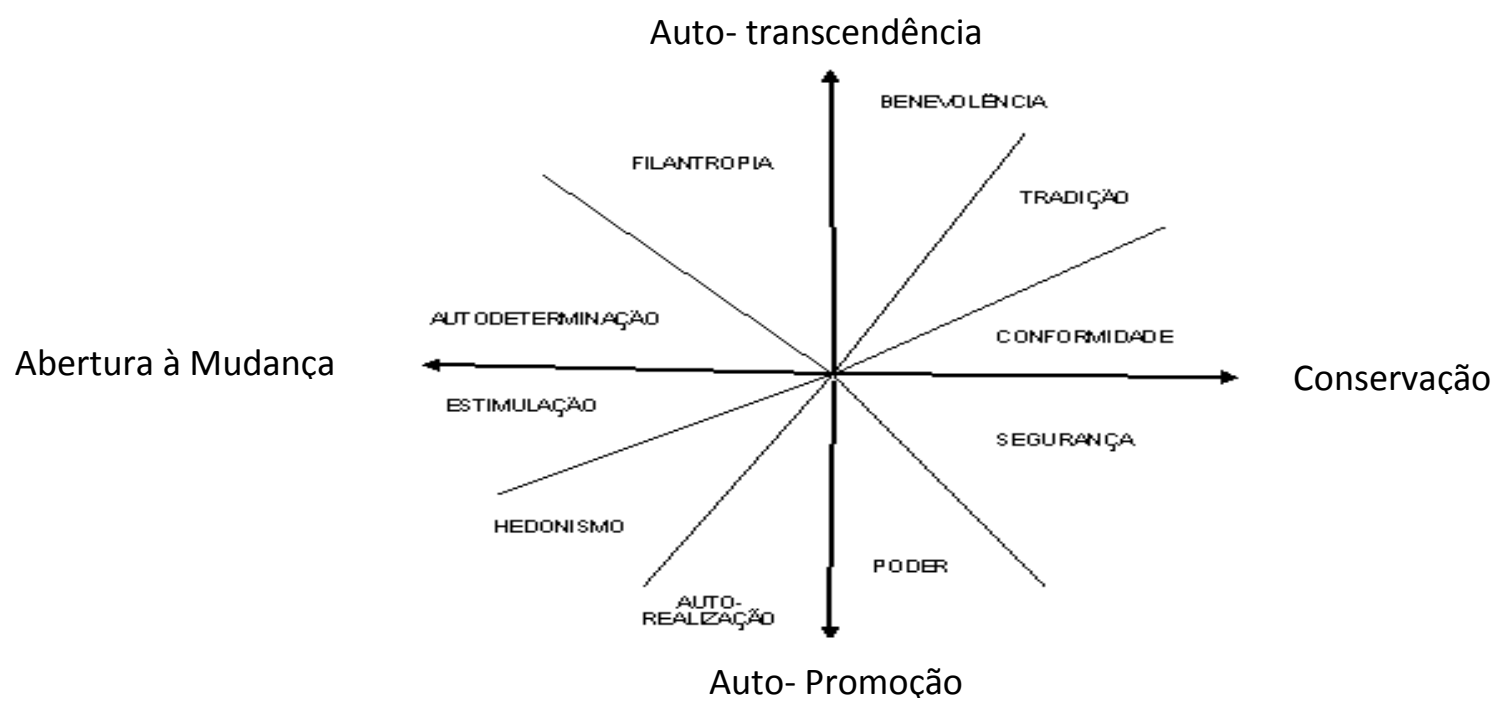

Fonte: Tamayo (2007, p.9).

O autor ressaltou que embora a escala de Rokeach e a de Schwartz representem um núcleo dos mais importantes valores humanos, parece ser necessário pesquisar a existência de possíveis valores específicos à cultura brasileira. $\mathrm{O}$ autor identificou valores que parecem ser característicos da cultura brasileira, entrevistou individualmente vinte educadores e ministros de diversas afiliações religiosas. Os sujeitos foram questionados sobre a existência de um ou mais valores que pudessem ser considerados como específicos aos brasileiros.

No presente estudo os aspectos que corroboraram para a escolha da utilização da escala de tipos motivacionais de Tamayo (2007) foram:

- Tradução e validação do instrumento SVS para o português do Brasil e inclusão de valores característicos do país e conseqüentemente aplicabilidade para os consumidores brasileiros (TAMAYO \& SCHWARTZ, 1993);

- Confiabilidade dos resultados das pesquisas realizadas por ele relacionando os valores com diversos comportamentos do consumidor (TAMAYO, 2007);

- Hierarquia dos valores com uma amostra brasileira, a hierarquia dos tipos motivacionais de valores e o procedimento utilizado para a identificação de valores característicos da cultura brasileira, bem como os resultados obtidos (TAMAYO, 1994).

REMark - Revista Brasileira de Marketing, São Paulo, v. 10, n. 3, p. 24-45, set./dez. 2011. 


\subsection{TEORIA DAS CADEIAS MEIOS-FIM}

Entre as propostas teórico-metodológicas que apresentam como referência as reflexões acerca dos valores, evidencia-se a teoria do modelo de cadeia meios-fim. Esta propõe que o conhecimento do produto ou serviço pelo consumidor é hierarquicamente organizado, atingindo diferentes níveis de abstração. O consumidor pode conhecer um produto por seus atributos, conseqüências de seu uso e valores pessoais. Os "meios" são objetos (produto) ou atividades (serviços) nas quais as pessoas se dedicam. Os "fins" são estados de espírito valorizados como felicidade, segurança, realização e pertencimento (GUTMAN, 1982; REYNOLDS \& GUTMAN, 1988).

A cadeia meios-fim busca explicar como a relação de um produto ou serviço facilita o alcance de estados finais desejados. Nesta abordagem os três níveis de associações se apresentam de forma distinta, onde dos atributos de produtos ou serviços (A) partem para conseqüências (C) e de consequiências partem para valores pessoais (V). Uma seqüência $\mathrm{A}-\mathrm{C}-\mathrm{V}$ forma o que Gutman (1982) denominou por cadeia meios-fim. Neste modelo podemos verificar a ênfase por que e como os atributos do produto são importantes, onde compreendemos os significados que estes têm na vida das pessoas.

\section{METODOLOGIA}

A pesquisa utilizou abordagem qualitativa através da entrevista em profundidade no levantamento dos dados e análise de conteúdo. A metodologia apresenta uma etapa quantitativa, uma vez que após as entrevistas, os dados foram tabulados em tabelas e dispostos em mapas hierárquicos, tais como diagramas de frequência.

O universo da pesquisa de campo foi os idosos, entre 60 e 85 anos, aposentados, que utilizam os serviços de atividades física, educativa e de dança, há no mínimo um ano para as atividades de dança e física, e seis meses para a atividade educativa (devido à duração dos cursos) e que sejam associados à Associação dos Aposentados e Pensionistas de Volta Redonda (AAPVR). Foram selecionados de forma intencional três segmentos de dez sujeitos para cada atividade, os quais estavam engajados no curso ou entretenimento para as atividades física, educativa e de dança.

REMark - Revista Brasileira de Marketing, São Paulo, v. 10, n. 3, p. 24-45, set./dez. 2011. 
A técnica laddering é considerada um processo trabalhoso e que exige habilidade por parte do pesquisador, tanto para a coleta, quanto para a análise dos dados, sendo bastante recomendada em pesquisas que abordem o valor para o cliente, nos moldes da cadeia meios-fins. Dibley \& Baker (2001) descrevem em seu trabalho o surgimento da técnica laddering. Segundo os autores (2001), a técnica teve origem no trabalho de Kelly (1955) que, atuando como pesquisadora na área da psicoterapia, elaborou uma teoria geral denominada Teoria dos Construtos Pessoais (Personal Construct Theory na língua inglesa). Baseada em 25 anos de clínica, para interpretar as experiências dos indivíduos. 


\section{ANÁLISE DOS RESULTADOS}

\subsection{CONSTRUÇÃO DOS MAPAS HIERÁRQUICOS DE VALOR}

Figura 2 - Mapa Hierárquico da Atividade de Informática

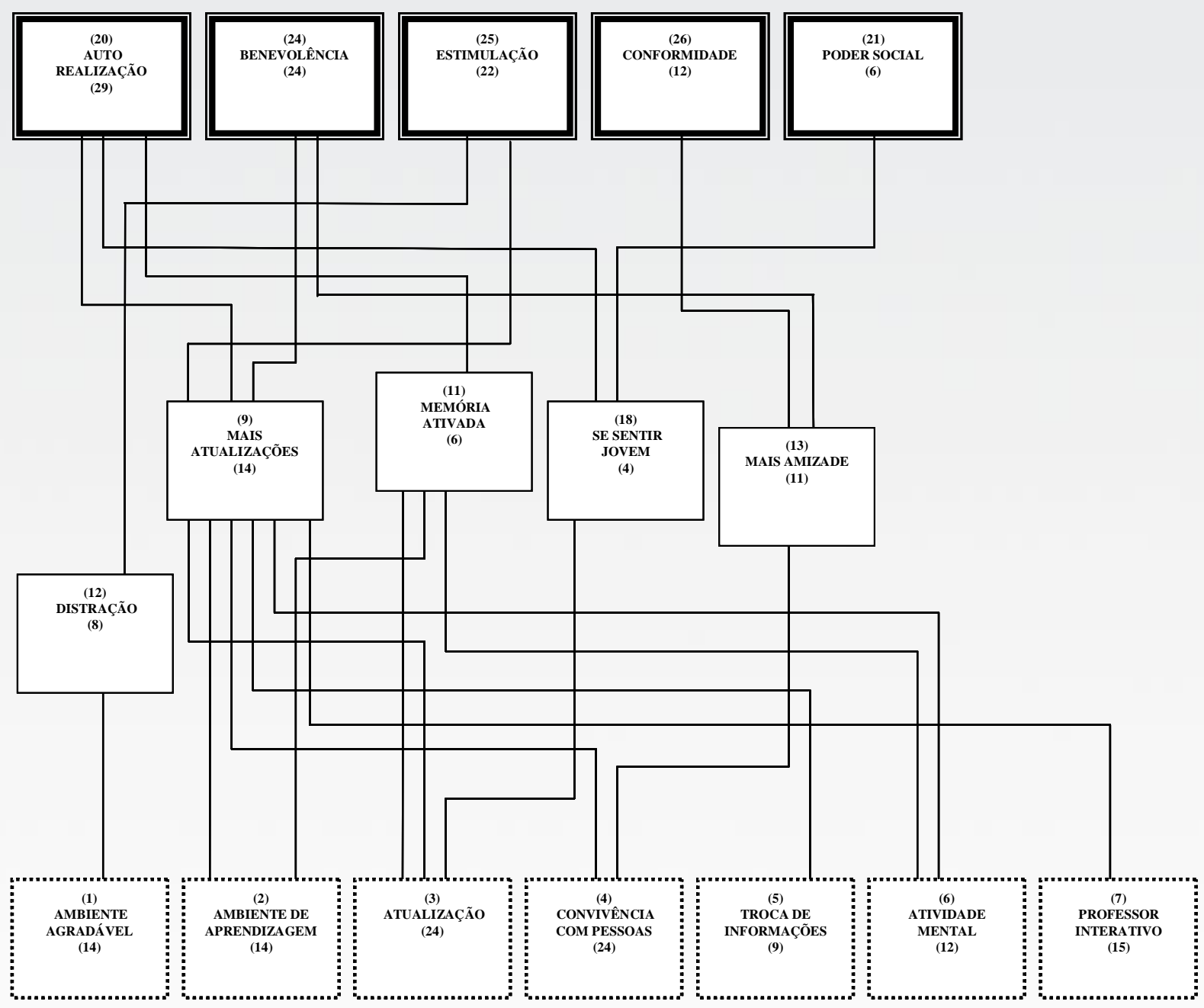

Fonte: Elaborada pela autora.

REMark - Revista Brasileira de Marketing, São Paulo, v. 10, n. 3, p. 24-45, set./dez. 2011. 
Figura 3 - Mapa Hierárquico da Atividade de Dança

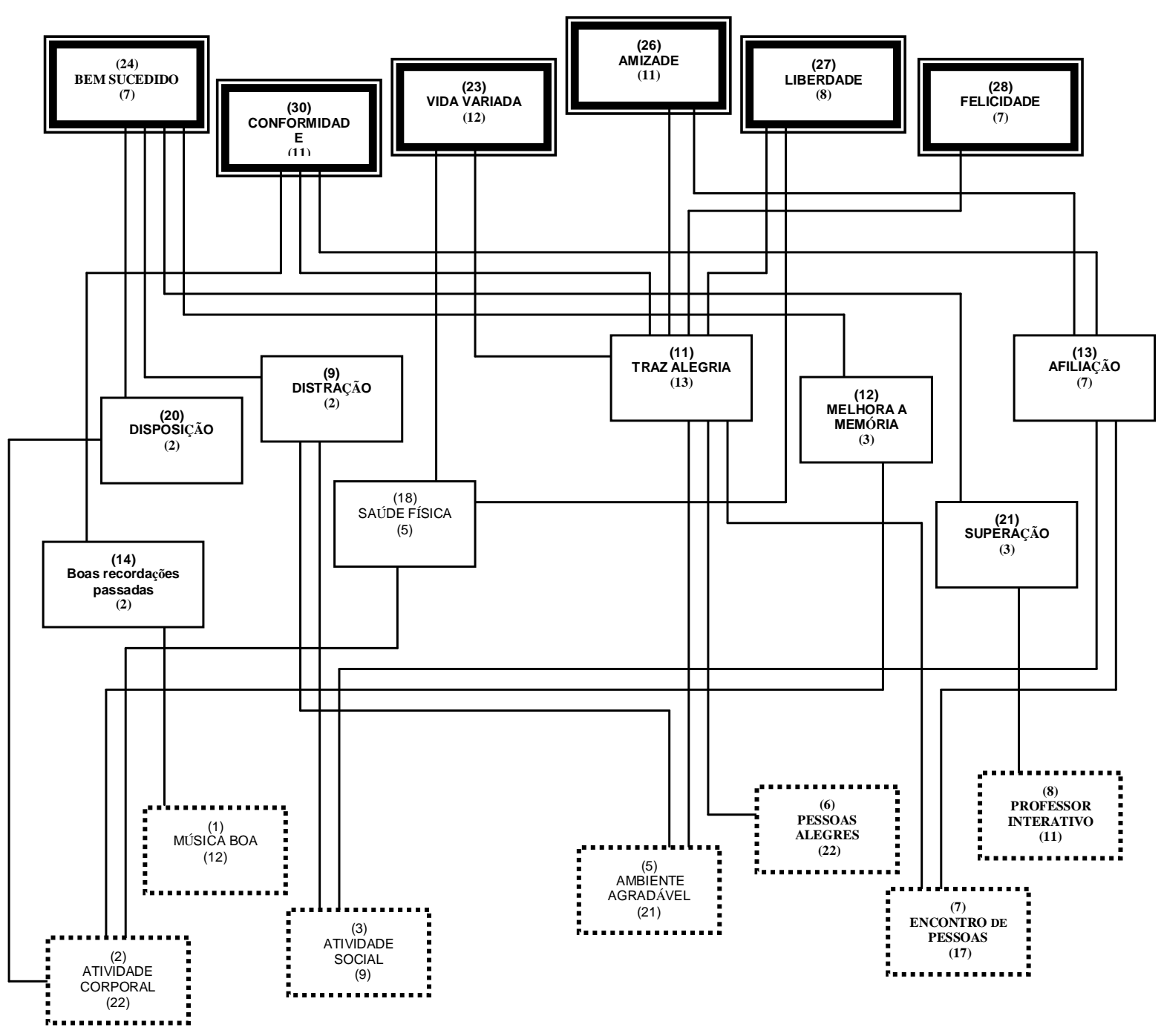

Fonte: Elaborada pela autora.

REMark - Revista Brasileira de Marketing, São Paulo, v. 10, n. 3, p. 24-45, set./dez. 2011. 
Figura 4 - Mapa Hierárquico da Atividade de Ginástica

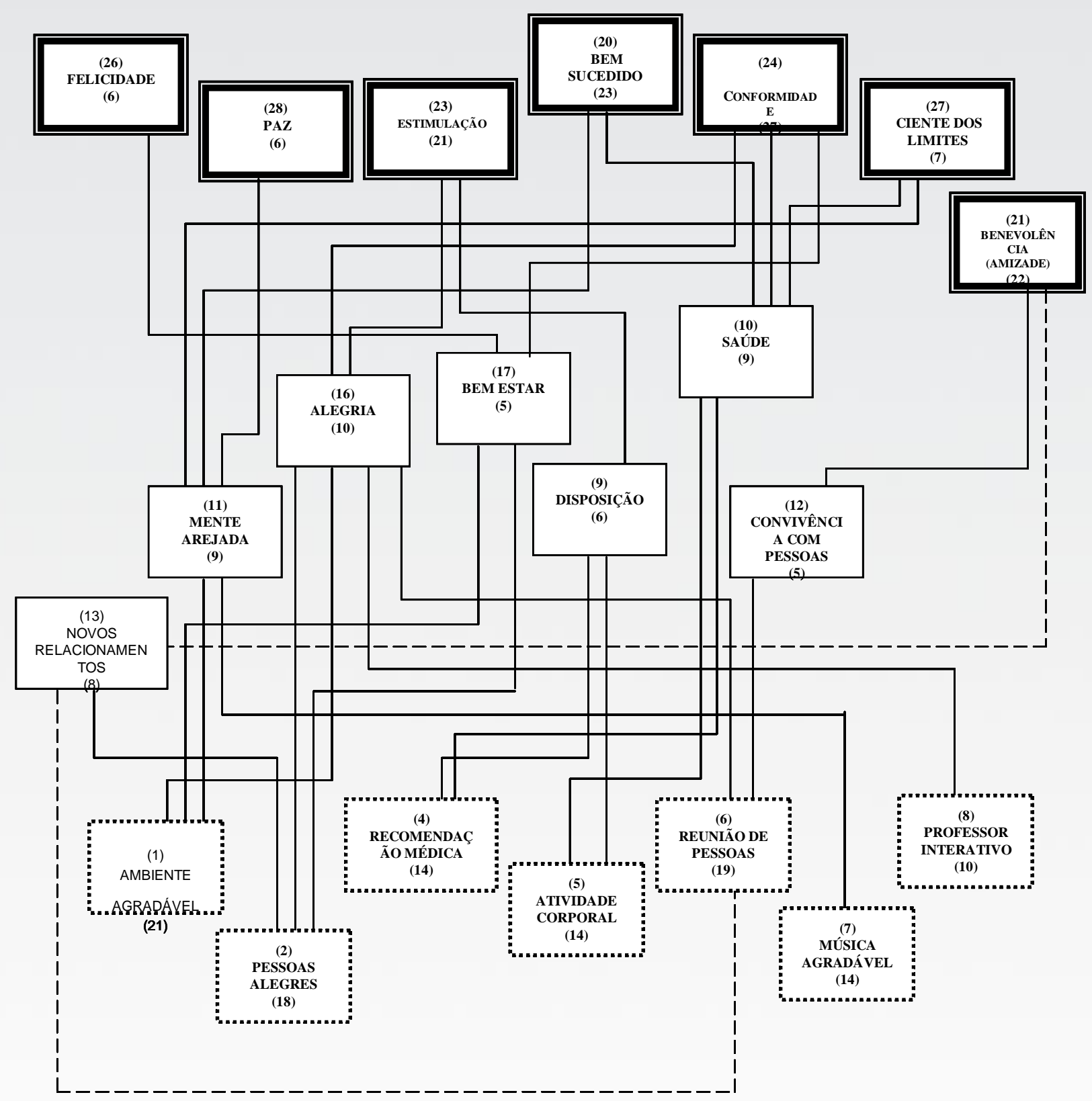

Fonte: Elaborada pela autora.

De acordo com os mapas hierárquicos de valor, o quadro 1 apresenta os valores pessoais identificados em cada atividade.

REMark - Revista Brasileira de Marketing, São Paulo, v. 10, n. 3, p. 24-45, set./dez. 2011. 
Quadro 2 - Valores pessoais identificados em cada atividade

\begin{tabular}{c|c|c}
\hline $\begin{array}{c}\text { ATIVIDADE } \\
\text { DE INFORMÁTICA }\end{array}$ & $\begin{array}{c}\text { ATIVIDADE } \\
\text { DE DANÇA }\end{array}$ & $\begin{array}{c}\text { ATIVIDADE } \\
\text { DE GINÁSTICA }\end{array}$ \\
\hline $\begin{array}{c}\text { Auto - realização } \\
\text { (bem sucedido) }\end{array}$ & $\begin{array}{c}\text { Auto - realização } \\
\text { (bem sucedido) }\end{array}$ & $\begin{array}{c}\text { Auto - realização } \\
\text { (bem sucedido) }\end{array}$ \\
\hline $\begin{array}{c}\text { Estimulação } \\
\text { (vida variada) }\end{array}$ & $\begin{array}{c}\text { Estimulação } \\
\text { (vida variada) }\end{array}$ & $\begin{array}{c}\text { Estimulação } \\
\text { (vida variada) }\end{array}$ \\
\hline Conformidade & Conformidade & Conformidade \\
\hline Benevolência (amizade) & Benevolência (amizade) & Benevolência (amizade) \\
\hline $\begin{array}{c}\text { Poder social } \\
\text { (reconhecimento social) }\end{array}$ & $\begin{array}{c}\text { Autodeterminação (liberdade e } \\
\text { independência) }\end{array}$ & Tradição (ciente dos limites) \\
\hline- & Felicidade (hedonismo) & Felicidade (hedonismo) \\
\hline- & & Filantropia (paz) \\
\hline
\end{tabular}

Fonte: Elaborado pela autora.

Dentre os valores específicos de cada atividade temos:

- PODER SOCIAL $\Rightarrow$ Os idosos participantes desta atividade se sentem reconhecidos pela sociedade (amigos, familiares e autoridades) como sendo pessoas ativas, engajadas na modernidade, é como se ocupassem uma posição de destaque através da sua participação na informática, pois se sentem importantes quando saem de casa com a blusa e com a pasta do curso. Quando conseguem fazer sozinhos o que aprenderam, se sentem auto-realizados.

- AUTO-REALIZAÇÃO => O sucesso pessoal na dança é obtido através de conseguirem guardar os passos, acompanhar o ritmo, se movimentarem e se alegrarem, comportamentos que são mais difíceis de ter nesta fase da vida, em decorrência das limitações físicas e psicológicas (MOSCHIS, 1994). Os idosos querem ser bem sucedidos, buscam experiências novas (NEUGARTEN, 1968).

- ESTIMULAÇÃO => Os idosos necessitam de viverem em novidade de vida, ou seja, de estar sempre vivenciando momentos diferentes, que proporcione a eles vontade de viver. A estimulação esteve constantemente na fala junto a: troca de informações, atualização, novos relacionamentos, reunião de pessoas,

REMark - Revista Brasileira de Marketing, São Paulo, v. 10, n. 3, p. 24-45, set./dez. 2011. 
pessoas alegres e mais amizades. Há uma busca por atividades que preencham o seu tempo livre e que constituam novas experiências (FLEISCHER \& PIZAM, 2002).

- BENEVOLÊNCIA $\Rightarrow$ O idoso tem como meta a busca pelo bem estar de pessoas íntimas (TAMAYO, 2007). Se auto-realiza em ver o bem estar de pessoas por quem tem amizade. Os idosos são solidários, percebem que "o querer bem ao próximo só engrandece a alma", "traz alegria e paz ao coração" e foi identificado nas três atividades, porque em sua maioria, em tudo que os idosos realizam se encontra implícito este desejo de se sentir bem e de ver o bem do próximo.

- CONFORMIDADE $\Rightarrow$ O idoso controla seus impulsos e comportamentos próprios em conformidade com as expectativas sociais (TAMAYO, 2007). No decorrer de toda vida aprendemos a nos comportar de acordo com as expectativas que as pessoas, que estão ao nosso redor, têm em relação aos nossos comportamentos, e permanecemos com essa cultura na fase madura de uma forma equilibrada, ou seja, consciente, atenuando problemas que poderiam surgir caso não se comportassem como tal. É o caso dos idosos que freqüentam lugares e eventos voltados para a terceira idade (SMITH \& MOSCHIS, 1991).

- AUTODETERMINAÇÃO $\Rightarrow$ Trata-se da independência de pensamento, ação e opção. A independência é um fator importante na terceira idade para este grupo, e ainda, independente em tudo faz diferença para o cotidiano para que se auto-realizem. Na dança se sentem livres, a sensação de liberdade traz a percepção de independência nos movimentos que realizam em sintonia com a música. E na informática, a independência de poderem conversar com muitas pessoas através do computador, sem depender exclusivamente do contato pessoal, encontrar outros meios de se comunicarem com pessoas e fazerem amizades.

- TRADIÇÃO => A meta é alcançar o respeito e a aceitação dos ideais e costumes de sua sociedade (grupo ao qual pertence) (TAMAYO, 2007). O idoso pertencente a esse grupo é consciente dos limites que tem em decorrência do processo de envelhecimento biológico (MOSCHIS, 1994),

REMark - Revista Brasileira de Marketing, São Paulo, v. 10, n. 3, p. 24-45, set./dez. 2011. 
sendo orientado por um professor com experiência profissional com a fase madura cumprindo exercícios que estão dentro do limite do seu limite. Os idosos se sentem mais a vontade, devido a todos que participam estarem na mesma faixa etária.

- HEDONISMO => Trata-se da gratificação de necessidades físicas transformada em valores socialmente reconhecidos, como o prazer. Nestas duas atividades os idosos atingem o prazer quando realizam os exercícios e os passos. É como expressar que "eu posso fazer", "eu consigo ainda" e "faço mais que muito jovem por aí". Eles conseguem atingir uma felicidade que descrevem como sendo palpável através do sorriso, do abraço e do aceno das mãos (MOSCHIS, 2003).

\section{CONSIDERAÇÕES FINAIS}

O objetivo principal desta pesquisa foi identificar as diferenças entre os valores pessoais do consumidor idoso com motivação utilitária e com motivação hedônica, na preferência pela participação em atividades física, educativa e de dança. Este objetivo foi atingido através da aplicação da técnica laddering.

Os consumidores idosos, que participam das três atividades se sentem motivados na compra de serviços que favoreçam novas amizades, o compartilhamento de vontades, desejos e necessidades, e ainda momentos diferenciados, com novidades que estimulem sentimentos como alegria, bem estar e ânimo.

Os sujeitos da atividade de informática, preferem atividades que promova o exercício mental e principalmente a capacidade de raciocínio, e acesso ao mundo moderno. A atividade de informática, por ser um curso moderno, que promove a inserção das pessoas no mundo atual, atrai os consumidores em geral que precisam ter mais conhecimento no manuseio das ferramentas disponíveis no mercado de trabalho. O consumidor idoso apresenta como meta o desejo de ser reconhecido socialmente e satisfazer uma necessidade pessoal de estar no mesmo nível de conhecimento das pessoas mais novas e ativas no mercado de trabalho. É como se de uma forma prazerosa mantivessem esta atividade mental. A partir da análise de conteúdo das entrevistas, ficou claro que o consumidor idoso da informática valoriza em nível mais elevado os benefícios

REMark - Revista Brasileira de Marketing, São Paulo, v. 10, n. 3, p. 24-45, set./dez. 2011. 
utilitários, enquanto os consumidores da ginástica e da dança expressam um estado de espírito vivenciado na experiência do momento em que participam das atividades em grupo.

Os sujeitos da atividade de ginástica, são dispostos a consumir serviços que favoreçam sua saúde e ao mesmo tempo oportunize novas amizades e momentos com novidades e ainda, compram e consomem serviços que apresentam oportunidade de experiências positivas em relação a estados afetivos como: alegria, paz, tranqüilidade e bem estar. A meta motivacional felicidade foi destacada como muito importante, representando o desejo de viverem felizes os dias que ainda têm de vida, consumindo tudo aquilo que gostam e que traz prazer. São consumidores que se sentem estimulados por realizar compras em locais onde os prestadores dos serviços demonstrem simpatia e alegria, pontuam que se sentem entusiasmados e acabam comprando mais pelo tratamento que recebem e pela certeza de se sentirem bem no momento da compra.

Os sujeitos da atividade de dança são consumidores atraídos pela compra de serviços que favoreçam a independência e a sensação de liberdade. Gostar de estar com pessoas alegres foi um atributo que foi destacado por todos os participantes, tanto nesta quanto nas demais atividades.

Concluímos que esta pesquisa contribui para o avanço da ciência da Administração, na área de marketing e setor de serviços para idosos, servindo às organizações, no sentido de avaliar, melhorar e aprimorar os serviços destinados ao consumidor idoso. Os valores, como alvos que os consumidores querem atingir utilizando determinado serviço ou produto, são fundamentais para o posicionamento de novos serviços.

\section{REFERÊNCIAS}

AMARAL, B. L.; NIQUE, W. M., E-Commerce: Atributos Determinantes na Utilização da Internet como Canal de Compra, XXIV ENANPAD, Florianópolis, 2000.

BOTSCHEN, G; THELES, E. M.; PIETERS, R. Using means-end structures for benefit segmentation an application to services. European Journal of Marketing, Bladford, v.33, n. 1-2, p. 38-58, 1999.

DIAS, V.K.; SCHWARTZ, G. M. O idoso e sua concepção de lazer. Revista Kinesis, n.27, p. 7895, 2002.

Considerações sobre o lazer de idosos: inclusão ou exclusão? In: ENCONTRO NACIONAL DE RECREAÇÃO E LAZER, 16, 2004, Salvador. Anais ... Salvador: UFBA, 2004.

REMark - Revista Brasileira de Marketing, São Paulo, v. 10, n. 3, p. 24-45, set./dez. 2011. 
DIBLEY, A., BAKER, S. Uncoring the links between brand choice and personal values among young British and Spanish girl. Journal of Consumer Behavior, v. 1, n. 1, p. 77 - 93, 2001.

DOLL et al. Estudos interdisciplinares do envelhecimento. Porto Alegre, v. 12, p. 7 - 33, 2007.

FARIA, Décio Luiz Mello Peixoto. Estou aposentado! E agora? In: ENCONTRO NACIONAL DOS PROGRAMAS DE PÓS-GRADUAÇÃO EM ADMINISTRAÇÃO - ENANPAD. Curitiba. Anais ... Curitiba: ANPAD, 2004.

GUTMAN, J. A. A means-end chain model based on consumer categorization processes. Journal of Marketing, v.46, n.2, p. 60-72, 1982.

HINKLE, D. The change of personal constructs the view point of theory of construct implications. Unpublished PhD Thesis. Ohio State University, 1965.

JOLIBERT, A.; BAUMGARTNER, G. Values, motivations and personal goals: revised. Psychology and Marketing, v.14, n.7, p. 675, 1997.

MENDONÇA, S. N. T. G.; TEIXEIRA, E. Ampliando a compreensão do processo de vida do idoso e de suas necessidades. Revista Brasileira de Crescimento e Desenvolvimento Humano, São Paulo, v.12, n.2, 2002.

MOSCHIS G. P. Gerontographics - A scientific approach to analyzing and targeting the mature market. Journal of Services Marketing, v.6, n.3, p.17-26, Summer 1992.

Marketing to older consumers: a handbook of information for strategy development. Westport: CT, Quorum Books, 1992.

"Consumer behavior in later life: multidisciplinary contributions and implications for research", Journal of the Academy of Marketing Science, v.22, n.3, p. 195-204, 1994.

Gerontographics: life-stage segmentation for marketing strategy development.

Westpot, CT: Quorum Books, 1996.

Marketing to older adults: an updated overview of present knowledge and practice. Journal of Consumer Marketing. v. 20, n.6, p. 516-525, 2003.

NEUGARTEN, Bernice. Middle Age and Aging. Chicago: University of Chicago Press, 1968.

Organização das Nações Unidas (ONU). Disponível em wwww.onu.org. Acesso em: 09 /08/ 2008.

Organização Mundial da Saúde (OMS). Disponível em www.oms.org. Acesso em: 10/08/2008.

PAPALÉO NETTO, M. Gerontologia - A Velhice e o Envelhecimento em visão globalizada. São Paulo. Atheneu, 1996.

REYNOLDS, T. J.; GUTMAN, J. Laddering theory, method, analysis and interpretation. Journal of Advertising Research, New York, v. 28, n.1, p. 11-31, Fev/Mar. 1988.

REMark - Revista Brasileira de Marketing, São Paulo, v. 10, n. 3, p. 24-45, set./dez. 2011. 
ROKEACH, M.J. The nature of human value. New York: Free Press, 1973..

SCHEWE, C. D. Strategically Positioning Your Way into the Aging Marketplace. Business Horizons, v. 34, p. $62-65,1991$.

SCHEWE, C. D.; BALAZS, A.L. Role transitions in older adults: a Marketing opportunity. Psychology \& Marketing, USA, v.9, n.2, p. 85-99, 1992.

SCHIFFMAN, L. G.; KANUK, L. L. Comportamento do consumidor. Rio de Janeiro: LTC, 2002.

SHETH, J. N.; MITTAL, B.; NEWMAN, B. I. Comportamento do cliente: indo além do comportamento do consumidor, Rio de Janeiro: Atlas, 2001.

TAMAYO, A. Hierarquia dos valores transculturais e brasileiros. Psicologia: Teoria e pesquisa, v.23, n.1, p. $7-15,2007$.

TAMAYO, A; PASCHOAL, T. A relação da motivação para o trabalho com as metas do trabalhador. Revista de Administração Contemporânea, 7, 33-54, 2003.

TAMAYO, A. SCHWARTZ, S. H. Estrutura motivacional dos valores humanos. Psicologia: Teoria e Pesquisa, v.9, n.2, p. 329 - 348, 1993.

WELLS, W. D.; PRENSKY, D. Consumer Behavior. New York: John Wiley \& Sons, 1996.

WOODRUFF, R. B.; GARDIAL, S. F. Know your customer: new approaches to understanding customer value and satisfaction. Malden: Blackwell Business, 1996.

VALETTE-FLORENCE, P.; RAPACHI, B. Improvements in Means-End Chain Analysis. Using Graph Theory and Correspondence Analysis. Journal of Advertising Research, p. 30-45, 1991.

VELUDO-DE-OLIVEIRA, T. M.; IKEDA, A. A. Usos e limitações do método laddering. Revista de Administração Mackenzie, p. 199-222, 2004.

VRIENDS, M.; HOFSTEDE, F. T. Linking attributes, benefits and consumer values. Journal of Marketing Research, v. 12, n. 3, p. 4-10, 2000.

ZEITHAML, V. A. Consumer Perceptions of Price, Quality, and Value: a means-end model and synthesis of evidence. Journal of Marketing, v. 52, n. 2, p. 2 - 22, 1988.

REMark - Revista Brasileira de Marketing, São Paulo, v. 10, n. 3, p. 24-45, set./dez. 2011. 


\title{
PHYSICAL ACTIVITY, EDUCATIONAL AND DANCE: A STUDY OF ELDERLY CONSUMERS PERSONAL VALUES
}

\begin{abstract}
The purpose of this research is to identify personal values of aged consumers that participate in physical, educational, and dance activities, analyzing them by the hedonic and utilitarian motivational aspects. The Means-End Chain Theory of Gutman (1982) has been chosen for this thesis, which uses the technique of laddering in interviews and content analysis of three segments with ten aged consumers duly engaged in the activities above. Based on the Hierarchy Value Map (HVM), it was possible to observe that the values and benefits associated with the participation in each activity are both of individual and collective interests and both have hedonic and utilitarian natures. The final result revealed the existence of convergent and divergent values, demonstrating the heterogeneous profile of the elderly consumers. This established that culture, life experiences, and current realities enhance the manifestation of a personal value on them. It was also observed in this research that during the acquisition and use of services, the aged demonstrated that what they really want, as a purpose, was to gain new friendships and new moments of their lives.
\end{abstract}

Key-words: Personal behavior of the aged consume; Personal values; Physical activities; Educational activity and activity of dance.

Data do recebimento do artigo: 27/07/2011

Data do aceite de publicação: 14/10/2011

REMark - Revista Brasileira de Marketing, São Paulo, v. 10, n. 3, p. 24-45, set./dez. 2011. 